studies were conducted in developing countries, most did not provide preferential access to researchers from there.

Conclusion A useful DAP should encompass complex issues ranging from ethical and legal to feasibility and practicability while remaining user-friendly to encourage collaboration. Giving consideration to researchers from countries involved in the study will promote international collaboration which will facilitate local research and enhance epidemiological knowledge.

\section{2-5.5 ESTIMATION OF THE BURDEN OF OCCUPATIONAL CANCER IN GREAT BRITAIN}

doi:10.1136/jech.2011.142976a.74

${ }^{1} \mathrm{~L}$ Rushton, ${ }^{*} \mathrm{~S}$ Hutchins, ${ }^{2} \mathrm{~S}$ Bagga, ${ }^{2} \mathrm{R}$ Bevan, ${ }^{3} \mathrm{~T}$ Brown, ${ }^{4} \mathrm{~J}$ Cherrie, ${ }^{2} \mathrm{P}$ Holmes, ${ }^{1} \mathrm{~L}$ Fortunato, ${ }^{2} \mathrm{R}$ Slack, ${ }^{4} \mathrm{M}$ Van Tongeren, ${ }^{3} \mathrm{C}$ Young. ${ }^{1}$ Imperial College London, London, UK; ${ }^{2}$ Institute of Environment and Health, Cranfield University, Cranfield, UK; ${ }^{3}$ Health and Safety Laboratory, Buxton, UK; ${ }^{4}$ Institute of Occupational Medicine, Edinburgh, UK

Introduction Prioritising control of occupationally-related cancers should be evidence based. We have estimated the current burden of cancer in Great Britain attributable to occupation for IARC group 1 and $2 \mathrm{~A}$ carcinogens.

Methods We calculated attributable fractions and numbers for mortality/incidence using risk estimates from published literature and national data sources to estimate proportions exposed.

Results Cancer deaths attributable to occupation in 2005 are $5.3 \%$ (8023) (men: 8.2\% (6366); women 2.3\% (1657)). Attributable incidence estimates are 13694 (4.0\%) cancer registrations (men: 10074 (5.7\%); women $3620(2.1 \%))$. Occupational attributable fractions are over $2 \%$ for mesothelioma, sinonasal, lung, nasopharynx, breast, non-melanoma skin, bladder, oesophagus, soft tissue sarcoma and stomach cancers. Asbestos, shift work, mineral oils, solar radiation, silica, diesel engine exhaust, coal tars and pitches, occupation as a painter or welder, dioxins, environmental tobacco smoke, radon, tetrachloroethylene, arsenic and strong inorganic mists each contribute $100+$ registrations. Industries/occupations with over 200 cancer registrations include construction, women's shift work, metal working, personal/household services, mining, land transport, printing/publishing, retail/hotels/restaurants, public administration/defence, farming and several manufacturing sectors.

Conclusions This study is the first detailed cancer burden study using all IARC 1 and 2A carcinogens and quantifying the contribution of individual industry sectors. Our methodology provides a basis for adaptation for use in other countries and global occupational burden estimation and for extension to include social and economic impact evaluation. The results highlight specific carcinogenic agents and the occupational circumstances and industrial areas where exposures to these agents occurs, facilitating prioritisation of risk reduction strategies.

\section{2-5.6 PUBLIC G00D, PERSONAL PRIVACY: A CITIZENS DELIBERATION ABOUT USING MEDICAL INFORMATION FOR PHARMACOEPIDEMIOLOGICAL RESEARCH}

doi:10.1136/jech.2011.142976a.75

L Parkin, ${ }^{*}$ C Paul. Department of Preventive and Social Medicine, University of Otago, Dunedin, New Zealand

Introduction Epidemiologists have long argued for access to personal health data to monitor, investigate, and improve the public health. At the same time, legislation and ethical guidelines have increasingly been framed in terms of protecting the privacy rights of individuals, rather than in terms of the public interest in the results of research. A 2002 Nuffield Trust report on the secondary use of medical data recommended a dialogue with the public about the arguments for use without consent and the appropriate safeguards. In 2006, the
UK Academy of Medical Sciences noted that evidence regarding public attitudes towards the use of medical information in research was still largely absent, and the investigations that had been undertaken asked undifferentiated questions which were not adequate to assess attitudes towards different types of research conducted by different groups for different purposes.

Methods We took up the challenge of having a dialogue with the New Zealand public about the balance between the public interest and privacy arguments, using a citizens' jury approach. A 3-day hearing was held to explore public views about the use of medical information for a specific purpose - researching the safety of medicines. Results The jury unanimously concluded that publicly-funded researchers should be permitted to use medical information about identifiable people, without their consent, for the above purposeproviding existing ethical guidelines and relevant laws are followed. Conclusions This outcome suggests that an informed public does not place personal privacy above societal benefits in the particular circumstance of medicines' safety research.

\subsection{MATERNAL AND CHILD HEALTH RISK FACTORS FOR PREGNANCY OUTCOME}

\section{Chair: Prof. Jill Pell, UK \\ 02-6.1 A SECOND CHANCE? PROBABILITY OF A LIVE BIRTH FOLLOWING INITIAL PREGNANCY LOSS: SURVIVAL ANALYSIS OF SCOTTISH NATIONAL DATA}

doi:10.1136/jech.2011.142976a.76

S Bhattacharya, ${ }^{*}$ D McLernon. University of Aberdeen, Aberdeen, Scotland, UK

Objective To ascertain the chance of a second pregnancy resulting in live birth following pregnancy loss

Methods Scottish data on all women whose first pregnancy occurred between 1981 and 2000 were linked to records of a subsequent pregnancy. The exposed cohorts comprised women with a first ectopic pregnancy, miscarriage, stillbirth or termination. The unexposed cohort comprised women who had an initial live birth. Kaplan-Meier curves of time to second pregnancy outcome and live birth from the date of first pregnancy were constructed. Cox's proportional hazards models were used to calculate the HR with $95 \%$ $\mathrm{CI}$ of any second pregnancy and live birth. The reference category was women whose first pregnancy ended in a live birth.

Results There were 667144 women with an initial live birth, 39530 with a miscarriage, 2969 with an ectopic first pregnancy, 3094 with a stillbirth and 78493 with termination of their first pregnancy. After adjusting for maternal age at first delivery, socioeconomic status and year of first pregnancy event, the HR ( $95 \% \mathrm{CI})$ of any second pregnancy was 1.35 (1.28 to 1.42), 2.24 (2.21 to 2.27), 2.44 (2.35 to 2.54), 0.66 (0.65 to 0.67) following ectopic, miscarriage, stillbirth and termination respectively. The adjusted hazards of a live birth following ectopic, miscarriage, stillbirth and termination were 0.71 (0.64 to 0.79 ); 0.92 (0.90 to 0.95 ), 1.17 (1.06 to 1.29 ), 0.62 (0.60 to 0.63 ) respectively. Conclusion Compared to an initial live birth, pregnancy loss increased the chance of another pregnancy (except in case of termination) but decreased the chance of a live birth (except stillbirth), emphasising the role of voluntary contraception in fertility patterns.

\section{$02-6.2$ WITHDRAWN}

